\section{Indications for breast magnetic resonance imaging in Brazil: past, present, and future}

\section{Dear Editor,}

In the previous issue of Radiologia Brasileira, Ferreira et al. ${ }^{(1)}$ described the main indications for breast magnetic resonance imaging (MRI) examination at a referral center for the diagnosis and treatment of breast cancer in Brazil. The results presented by those authors corroborate the findings of a previous study conducted by our group, carried out at another referral center in Brazil and published in the journal in $2011^{(2)}$. Although they were performed at facilities in different states and in different time periods (2014-2018 and 2008-2009, respectively), both studies showed that most breast MRI examinations performed in Brazil are requested for the evaluation of patients in whom the mammography and ultrasound findings are inconclusive. Although some studies have shown the benefit of MRI in some specific situations within that context ${ }^{(3,4)}$, that indication has little foundation in the literature and even in the Breast Imaging Reporting and Data System recommendations ${ }^{(5)}$. Other indications that are more well-established in the literature ${ }^{(6-8)}$, such as screening for high-risk patients, locoregional staging, and assessment of the response to neoadjuvant treatment, account for a lower proportion of the MRI examinations requested.

Both of the studies cited above were carried out at referral centers for cancer, which suggests that their findings cannot be extrapolated to all facilities in Brazil. However, the factors related to those findings merit further discussion. Unfortunately, the high cost and limited availability of breast MRI are still important limiting factors for the dissemination of the method in the country. Although breast MRI is already a well-established method, there are few facilities in Brazil where this examination is performed by trained professionals, which also impedes the dissemination of the method and even results in a lack of confidence on the part of the requesting physicians. There are even fewer facilities that perform imaging-guided biopsy of suspicious lesions that are detected on MRI and have not been identified by other methods (mammography and ultrasound), which makes the management of such lesions more difficult in some cases.

Updating the data from our previous study ${ }^{(2)}$, we observed that, among the 1,837 breast MRI examinations performed at our center between February 2019 and February 2020 (prior to the current pandemic), the main indications were as follows: diagnostic uncertainty after mammography or ultrasound, in 490 cases $(26.7 \%)$; surveillance after breast cancer treatment, in 423 cases $(23.0 \%)$; staging, in 255 cases $(13.9 \%)$; screening of highrisk patients, in 226 cases $(12.3 \%)$; and assessment of the response to neoadjuvant chemotherapy, in 145 cases $(7.9 \%)$. These data suggest a change in the profile of the tests requested over time, with a reduction in indications due to equivocal findings and a proportional increase in other indications. Therefore, we believe that better training and supervision at facilities that perform breast MRI, as well as greater dissemination and discussion of the most appropriate indications for the method among requesting physicians, can favor the optimized use of this resource, making it more cost-effective, in Brazil.

\section{REFERENCES}

1. Ferreira SS, Campos AM, Fernandes PL, et al. Indications for breast magnetic resonance imaging at a referral center for the diagnosis and treatment of breast cancer in Brazil. Radiol Bras. 2021;54:83-6.

2. Marques EF, Medeiros MLL, Souza JA, et al. Indications for breast magnetic resonance imaging in an oncology reference center. Radiol Bras. 2011 , $44: 363-6$

3. Bennani-Baiti B, Bennani-Baiti N, Baltzer PA. Diagnostic performance of breast magnetic resonance imaging in non-calcified equivocal breast findings: results from a systematic review and meta-analysis. PLoS One. 2016;11:e0160346.

4. Giess CS, Chikarmane SA, Sippo DA, et al. Breast MR imaging for equivocal mammographic findings: help or hindrance? Radiographics. 2016;36:943-56.

5. Morris EA, Comstock CE, Lee CH, et al. ACR BI-RADS ${ }^{\circledR}$ magnetic resonance imaging. In: ACR BI-RADS ${ }^{\circledR}$ Atlas, Breast Imaging Reporting and Data System. Reston, VA: American College of Radiology; 2013.

6. Sardanelli F, Boetes C, Borisch B, et al. Magnetic resonance imaging of the breast: recommendations from the EUSOMA working group. Eur J Cancer 2010;46:1296-316.

7. Mann RM, Balleyguier C, Baltzer PA, et al. Breast MRI: EUSOBI recommendations for women's information. Eur Radiol. 2015;25:3669-78.

8. Monticciolo DL, Newell MS, Moy L, et al. Breast cancer screening in women at higher-than-average risk: recommendations from the ACR. J Am Coll Radiol. 2018;15(3 Pt A):408-14.

\section{Almir Galvão Vieira Bitencourt ${ }^{1, a}$, Rubens Chojniak ${ }^{1, b}$}

1. Department of Imaging - A.C.Camargo Cancer Center, São Paulo, SP, Brazil. Correspondence: Dr. Almir Galvão Vieira Bitencourt. Departamento de Imagem - A.C.Camargo Cancer Center. Rua Professor Antônio Prudente, 211, Liberdade. São Paulo, SP, Brazil, 09015-010. Email: almir.bitencourt@accamargo.org.br.

a. https://orcid.org/0000-0003-0192-9885. b. https://orcid.org/0000-0002-8096-252X. http://dx.doi.org/10.1590/0100-3984.2021.0056

\section{Portal vein embolization, biembolization, and liver venous deprivation}

\section{Dear editor}

We read with great interest the article "Liver venous deprivation prior to hepatectomy: an interventional radiology procedure", authored by Alves et al. ${ }^{(1)}$, in a recent issue of Radiologia Brasileira. This is an excellent addition to the "Advances in Radiology" section of the journal, which highlights the latest developments in medical practice in Brazil. Liver regeneration prior to major hepatectomy is decisive in cancer management because it allows these potentially curative surgical procedures to be performed in otherwise inoperable patients, thus improving survival outcomes $^{(2)}$. Portal vein embolization (PVE), used for decades as a method of inducing liver hypertrophy ${ }^{(3)}$, has recently been used in combination with embolization of one or more hepatic veins ${ }^{(4)}$.

Alves et al. ${ }^{(1)}$ described concomitant PVE and proximal right hepatic vein embolization with a vascular plug. This technique might be more appropriately designated biembolization ${ }^{(5)}$, be- ing slightly different from liver venous deprivation (LVD). The LVD procedure has been described as: PVE plus proximal and distal embolization of the hepatic veins. Proximal embolization of the hepatic vein is accomplished with a vascular plug, as in biembolization, whereas distal embolization of the hepatic vein is achieved with N-butyl-cyanoacrylate (NBCA) plus lipiodol, as in $\mathrm{LVD}^{(2)}$. Why might this be relevant? Invariably, venovenous collaterals between liver segments V/VIII and IV are present ${ }^{(6)}$ and will increase in size after plug deployment ${ }^{(4)}$. Distal embolization with a liquid embolic agent (i.e., NBCA) not only eliminates flow in the target vein but also occludes those collaterals, which might have benefits in terms of liver hypertrophy induction. In addition, biembolization and LVD may require different technical approaches: LVD is usually performed through a percutaneous trans-hepatic approach ${ }^{(4,7)}$, making it easier to inject liquid embolic agents after plug deployment, whereas biembolization is performed through a transjugular approach (Figure 1).

Segment IV PVE, which was performed by Alves et al. ${ }^{(1)}$, has been reported to induce additional liver hypertrophy ${ }^{(8)}$. 


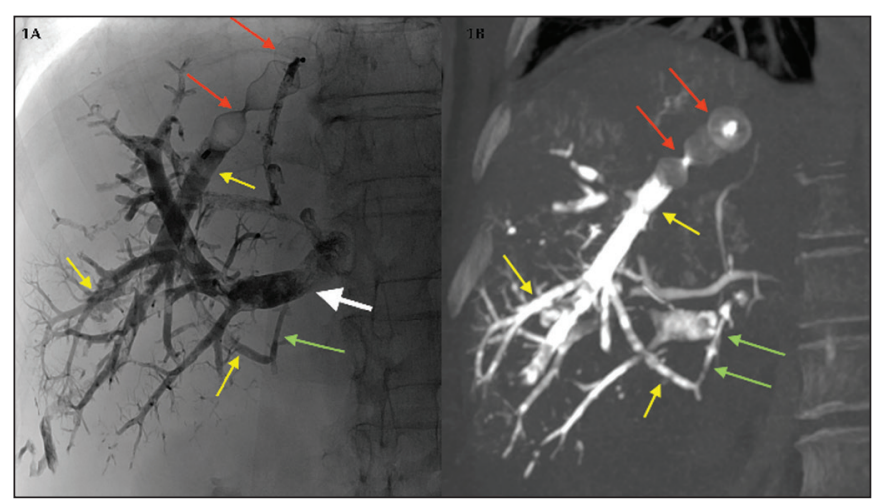

Figure 1. Fluoroscopic image (1A) obtained immediately after LVD and contrastenhanced coronal CT (1B) obtained 14 days after LVD. Note the vascular plug (red arrows) placed in the right hepatic vein for proximal embolization and NBCA plus lipiodol occluding the distal branches (yellow arrows). Note also NBCA plus lipiodol occluding a venovenous collateral (green arrows) and right portal vein embolization with NBCA plus lipiodol (white arrow).

However, segment IV embolization is controversial: the segment IV portal branches are usually numerous and tiny, which increases the procedure time and the degree of technical difficulty; liquid embolic agents are trickier to use, because any reflux would cause nontarget embolization of liver segments II and III; due to the degree of technical difficulty, suboptimal embolization of segment IV might be an issue ${ }^{(9)}$; and segment IV is the main territory for systemic-portal venous shunts, possibly decreasing the efficacy of the procedure ${ }^{(10)}$. To overcome the limitations of PVE of segment IV, a more aggressive form of LVD has been proposed-extended LVD $^{(11)}$ — which consists of LVD plus middle hepatic vein embolization. Extended LVD has been shown to be safe and highly effective, promoting an unparalleled $53.4 \%$ increase in liver volume within only seven days ${ }^{(11)}$.

Future studies focusing on patient selection are needed. When and how to choose from such a variety of interventional tools? How to best predict post-hepatectomy liver failure? How can we choose between volumetric computed tomography and liver function studies (e.g., ${ }^{99 \mathrm{~m}} \mathrm{Tc}$-mebrofenin hepatobiliary scintigraphy, gadoxetic acid-enhanced magnetic resonance imaging, and indocyanine green retention test) —or should we perform both? Most importantly, when is the liver ready for major surgery? How can we safely accelerate this preoperative process? Answering such questions are the reason for having multidisciplinary team meetings that allow personalized medical care, with input from different medical perspectives. We want to congratulate the authors not only for obtaining a regenerative outcome that allowed successful major hepatectomy within 41 days after embolization but also for highlighting the potential role and advantages of LVD versus PVE, providing grounds to expand future studies in this field ${ }^{(12)}$.

\section{REFERENCES}

1. Alves VPV, Azevedo A, Araujo DA, et al. Liver venous deprivation prior to hepatectomy: an interventional radiology procedure. Radiol Bras. 2021;54:62-3.

2. Giglio MC, Giakoustidis A, Draz A, et al. Oncological outcomes of major liver resection following portal vein embolization: a systematic review and metaanalysis. Ann Surg Oncol. 2016;23:3709-17.

3. Luz JHM, Gomes FV, Coimbra E, et al. Preoperative portal vein embolization in hepatic surgery: a review about the embolic materials and their effects on liver regeneration and outcome. Radiol Res Pract. 2020;2020:9295852.

4. Guiu B, Chevallier P, Denys A, et al. Simultaneous trans-hepatic portal and hepatic vein embolization before major hepatectomy: the liver venous deprivation technique. Eur Radiol. 2016;26:4259-67.

5. Le Roy B, Perrey A, Fontarensky M, et al. Combined preoperative portal and hepatic vein embolization (biembolization) to improve liver regeneration before major liver resection: a preliminary report. World J Surg. 2017;41: $1848-56$.

6. Gai YH, Cai SF, Guo WB, et al. Sonographic classification of draining pathways of obstructed hepatic veins in Budd-Chiari syndrome. J Clin Ultrasound. 2014;42:134-42.

7. Panaro F, Giannone F, Riviere B, et al. Perioperative impact of liver venous deprivation compared with portal venous embolization in patients undergoing right hepatectomy: preliminary results from the pioneer center. Hepatobiliary Surg Nutr. 2019;8:329-37.

8. Kishi I, Madoff DC, Abdalla EK, et al. Is embolization of segment 4 portal veins before extended right hepatectomy justified? Surgery. 2008;144:744-51.

9. de Baere T, Teriitehau C, Deschamps F, et al. Predictive factors for hypertrophy of the future remnant liver after selective portal vein embolization. Ann Surg Oncol. 2010;17:2081-9.

10. Breen DJ, Rutherford EE, Stedman B, et al. Intrahepatic arterioportal shunting and anomalous venous drainage: understanding the CT features in the liver. Eur Radiol. 2004;14:2249-60.

11. Guiu B, Quenet F, Escal L, et al. Extended liver venous deprivation before major hepatectomy induces marked and very rapid increase in future liver remnant function. Eur Radiol. 2017;27:3343-52.

12. Luz JHM, Gomes FG, Costa NV, et al. BestFRL trial: liver regeneration at CT before major hepatectomies for liver cancer-a randomized controlled trial comparing portal vein embolization with N-butyl-cyanoacrilate plus iodized oil versus polyvinyl alcohol particles plus coils. Radiology. 2021 April 6;204055. Online ahead of print.

\section{José Hugo Mendes Luz ${ }^{1, a}$, Tiago Bilhim, ${ }^{1, b}$}

1. Department of Interventional Radiology, Curry Cabral Hospital, and NOVA Medical School, Universidade NOVA de Lisboa, Lisbon, Portugal.

Correspondence: José Hugo Mendes Luz, MD. Hospital Curry Cabral - Serviço de Radiologia de Intervenção. Rua da Beneficência 8, 1069-166 Lisboa, Portugal. Email: jhugoluz@gmail.com / josehugo@rivoa.com.br.

a. https://orcid.org/0000-0002-1222-850X; b. https://orcid.org/0000-0003-3044-8474. http://dx.doi.org/10.1590/0100-3984.2021.0040

\section{Reply}

We received with great enthusiasm the Letter to the Editor "Portal vein embolization, biembolization, and liver venous deprivation”, authored by Dr. Luz and Dr. Bilhim. We certainly agree that the precise nomenclature for the procedure described in our paper should be "Portal vein embolization with hepatic vein biembolization". The added technique of distal embolization of the hepatic veins, described in liver venous deprivation, would likely represent further liver hypertrophy and probably better hepatic functionality than those achieved in the case we described. Our group has now standardized liver venous deprivation with a transhepatic approach as the technique of choice in such cases. In regard to the issue of hepatic segment IV embolization, we are of the same opinion (that it presents a technical challenge to the PVE procedure), and extended LVD with middle hepatic vein, rather than segment IV embolization, is now the preferred method in our department. Nevertheless, the theme of combined PVE and LVD (or biembolization) raises multiple questions and concerns, which will likely be addressed by prospective multicenter studies and collaborative multidisciplinary discussions to optimize medical care for the affected patients. We want to thank the authors for their interest in our paper, as well as for the perfectly highlighted issues, which further elevate the level of scientific debate in the area of interventional radiology.

\section{Vinicius de Pádua Vieira Alves ${ }^{1, a}$, André Azevedo ${ }^{2, b}$, Danilo Alves de Araujo ${ }^{1, c}$, Leonardo Azevedo Marcondes Rodrigues ${ }^{2, d}$, Feliciano Silva de Azevedo ${ }^{2, e}$}

1. Universidade Federal Fluminense (UFF), Niterói, RJ, Brazil. 2. Department of Interventional Radiology, Americas Medical City, Rio de Janeiro, RJ, Brazil.

Correspondence: Dr. Vinicius Alves. Universidade Federal Fluminense. Avenida Marquês do Paraná, 303, Centro. Niterói, RJ, Brazil, 24220-900. Email: vinpvalves@gmail.com.

a. https://orcid.org/0000-0001-8772-4770; b. https://orcid.org/0000-0001-6713-0342; c. https://orcid.org/0000-0001-6200-0186; d. https://orcid.org/0000-0003-1827-4264; e. https://orcid.org/0000-0001-8213-7921. 